\title{
Predicting Oxygen Off-stoichiometry and Hydrogen Incorporation in Complex Perovskite Oxides
}

Authors: Samantha L. Millican, ${ }^{1}$ Ann M. Deml, ${ }^{2,3}$ Meagan Papac, ${ }^{2,3}$ Andriy Zakutayev, ${ }^{2,3}$ Ryan O'Hayre, ${ }^{2}$ Aaron M. Holder, ${ }^{1,3}$ Charles B. Musgrave, ${ }^{1,3,4,5}$ and Vladan Stevanović ${ }^{2,3 *}$

\section{Affiliations:}

${ }^{1}$ Department of Chemical and Biological Engineering, University of Colorado, Boulder, Colorado 80309, USA

${ }^{2}$ Department of Metallurgical and Materials Engineering, Colorado School of Mines, Golden, Colorado 80401, USA

${ }^{3}$ Materials Science Center, National Renewable Energy Laboratory, Golden, Colorado 80401, USA

${ }^{4}$ Department of Chemistry, University of Colorado, Boulder, Colorado 80309, USA

${ }^{5}$ Renewable and Sustainable Energy Institute, University of Colorado, Boulder, Colorado 80309, USA

*Correspondence: vladan.stevanovic@ nrel.gov

\section{Supplemental Information}

\section{Methods}

For both oxygen and water, the chemical potentials at relevant temperatures and pressures are calculated according to:

$$
\mu_{i}=\mu_{i}^{e l}+\Delta \mu_{i}
$$

where $\mu_{i}^{e l}$ is the elemental phase chemical potential determined by the FERE method for oxygen and is the computed energy with the zero-point energy correction for water. ${ }^{1,2} \Delta \mu_{i}$ gives the change in the chemical potential with deviations from standard temperature and pressure assuming an ideal gas according to Equation (S2): ${ }^{3}$

$$
\Delta \mu_{i}(T, P)=\left[H_{0}+C_{p}\left(T-T_{0}\right)\right]-T\left[S_{0}+C_{p} \ln \left(\frac{T}{T_{0}}\right)\right]+k_{B} T \ln \left(\frac{P}{P_{0}}\right)
$$

where $\mathrm{H}_{0}, \mathrm{~S}_{0}$, and $\mathrm{C}_{\mathrm{p}}$ are the tabulated enthalpy, entropy, and heat capacity values for $\mathrm{O}_{2}$ and $\mathrm{H}_{2} \mathrm{O}$ at $\mathrm{T}_{0}=298 \mathrm{~K}$ and $\mathrm{P}_{0}=1 \mathrm{~atm} .^{4}$

The formation of an oxygen vacancy or proton interstitial results in the donation of two or one electrons, respectively, to the Fermi sea which pushes the Fermi energy up by an amount that depends on the DOS. The calculated shift in the Fermi energy $\left(\Delta E_{f}\right)$ is used to calculate a corrected defect formation energy for each defect. The addition of one electron upon proton interstitial formation inherently assumes that the hydrogen atom exists as a proton within the defect structure. This assumption has been validated for the materials and proton concentrations considered here by an analysis of the defect DOS which shows that the available hydrogen states are high in energy relative to $E_{f}$. In other systems or at very high $\mathrm{H}$ concentrations, this assumption may not hold. 
To validate our approach for higher defect concentrations, the vacancy formation energies of four randomly selected sets of vacancy positions were computed for comparison to the model with $3,5,8,11$, and 14 vacancies in the supercell $\left(\delta=0.11,0.19,0.30,0.41\right.$, and 0.52 in $\left.\mathrm{ABO}_{3-\delta}\right)$. These calculations of defect energies at a range of vacancy concentrations that exceed the dilute limit are not used as an input to the model, but are instead used as a comparison for the predicted defect concentrations obtained using the model.

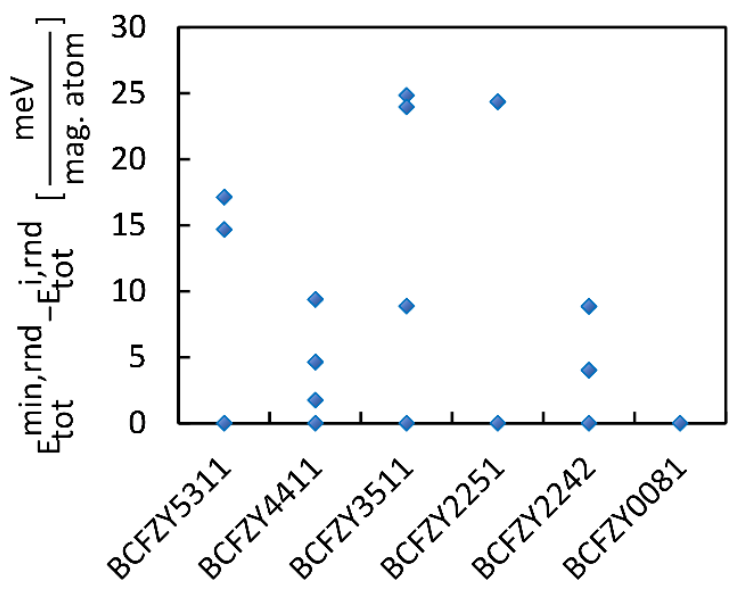

Figure S1. DFT+U calculated variation in the total energy of random magnetic configurations for six BCFZY compositions
Calculations were performed using $\mathrm{DFT}+\mathrm{U}$ within the plane wave periodic boundary condition approximation as implemented in the Vienna Ab-Initio Simulation Package (VASP). ${ }^{5}$ We utilized the Perdew-Burke-Ernzerhof (PBE) generalized gradient approximation exchangecorrelation functional and projector augmented wave (PAW) method, ${ }^{6,7}$ a $2 \times 2 \times 2$ MonkhorstPack $k$-point mesh ${ }^{8}$ together with a $450 \mathrm{eV}$ energy cutoff with total energies converged to less than $10^{-5} \mathrm{eV}$. A constant Hubbard correction of $\mathrm{U}=3$ $\mathrm{eV}$ was applied to $\mathrm{Fe}, \mathrm{Co}, \mathrm{Zr}$, and $\mathrm{Y}$ to more accurately describe onsite electron correlation in these systems. ${ }^{1}$ Spin degrees of freedom were treated explicitly with initialization of magnetic moments in high spin ferromagnetic and multiple random configurations. These materials are usually used in devices operating at temperatures well above their Néel or Curie temperatures and are thus expected to exhibit magnetic disorder. This expectation is consistent with experiments that have demonstrated these materials to be paramagnetic at relevant operating conditions $\left(>500^{\circ} \mathrm{C}\right)$, thus the paramagnetic (random) spin configurations were utilized for the defect analyses conducted herein. ${ }^{9-12}$ The total energy differences between paramagnetic configurations were on the order of $\sim 0.01 \mathrm{eV}$ per magnetic atom as shown in Figure S1, which is consistent with the results of previous studies. ${ }^{1,13}$ After relaxing the structures, a single-point calculation using the tetrahedron method with Blöch corrections to set partial occupancies was performed to obtain a more accurate prediction of the electronic density of states (DOS). Calculations utilized a $3 \times 3 \times 3$ expansion of the primitive cubic perovskite unit cell, which contained 135 atoms. These cells were occupied by random cation configurations based on the special quasirandom structure (SQS) generation algorithm as implemented in the Alloy Theoretic Automated Toolkit (ATAT). ${ }^{14-16}$ Four compositions of BCFZY and one composition each of BSFZ and BSCF were generated (see abbreviations for all compositions). Compositions were selected for comparison to available experimental data.

Thin films of $\mathrm{BaCo}_{1-\mathrm{x}-\mathrm{y}-\mathrm{z}} \mathrm{Fe}_{\mathrm{x}} \mathrm{Zr}_{\mathrm{y}} \mathrm{Y}_{\mathrm{z}} \mathrm{O}_{3}$ were synthesized in a combinatorial pulsed laser deposition chamber (Neocera) on $50.8 \times 50.8 \mathrm{~mm}^{2}$ fused quartz substrates, pre-heated by a radiative heater set to $850^{\circ} \mathrm{C}$. Custom-made $\mathrm{Ba}\left(\mathrm{Zr}_{\mathrm{x}} \mathrm{Y}_{\mathrm{y}} \mathrm{Co}_{\mathrm{z}} \mathrm{Fe}_{1-\mathrm{x}-\mathrm{y}-\mathrm{z}}\right) \mathrm{O}_{3-\delta}$ targets were ablated with a $248-\mathrm{nm}$ $\mathrm{KrF}$ excimer laser under $50 \mathrm{mTorr}$ oxygen pressure at a distance of $7.5 \mathrm{~cm}$ from the substrate, achieving film thicknesses in the range of $100-300 \mathrm{~nm}$. The laser energy density was $\sim 2 \mathrm{~J} / \mathrm{cm}^{2}$, fired at $10 \mathrm{~Hz}$. Thin film structures were characterized using a $\theta-2 \theta$ X-ray diffraction scan with $\mathrm{CuK} \alpha$ radiation in a Bruker D8 Discovery diffractometer. The most intense peak, corresponding to $\{110\}$ planes, was fit using a Gaussian model, and its position was used to calculate the cubic 
lattice constant. Experimental measurements for oxygen off-stoichiometry and lattice parameters for BSCF5582 $2^{17,18}$ and BSFZ5582 $2^{19,20}$ were taken from literature.

\section{Structural Properties}

Figure $\mathrm{S} 2$ shows the computed lattice parameters as compared to the lattice constants of thin films grown using pulsed laser deposition for all BCFZY, BSCF, and BSFZ compositions studied. Structures generated using randomized cation configurations and magnetic moments predict lattice parameters that exhibit the same trend as experimental values with changing composition. Computed lattice parameters are overestimated by $1.3 \%$ on average for all compounds studied. This is consistent with the previous studies indicating an overestimation of lattice parameters using PBE+U calculations. ${ }^{21}$ Comparison of the structures of BCFZY3511, BCFZY4411 and BCFZY5311 shows that substitution of Co in place of Fe has a negligible effect on the lattice parameters. The largest lattice parameter changes in BCFZY are predicted and measured for cases where $\mathrm{Co}$ or $\mathrm{Fe}$ is substituted for $\mathrm{Zr}$ or $\mathrm{Y}$ (e.g. BCFZY0081 compared to BCFZY2242, or BCFZY2251 compared to BCFZY3511). This is primarily due to the larger ionic radii of $\mathrm{Zr}^{4+}$ and $\mathrm{Y}^{3+}\left(0.72 \AA\right.$ and $0.90 \AA$, respectively) compared to $\mathrm{Co}^{4+}$ and $\mathrm{Fe}^{4+}(0.53 \AA$ and $0.58 \AA$, respectively). ${ }^{22}$ This is further reflected in the average computed metal-oxygen bond distances of $2.14 \AA, 2.27 \AA, 2.01 \AA$, and $2.07 \AA$ for $\mathrm{Zr}-\mathrm{O}$, Y-O, Co-O, and Fe-O bonds, respectively.

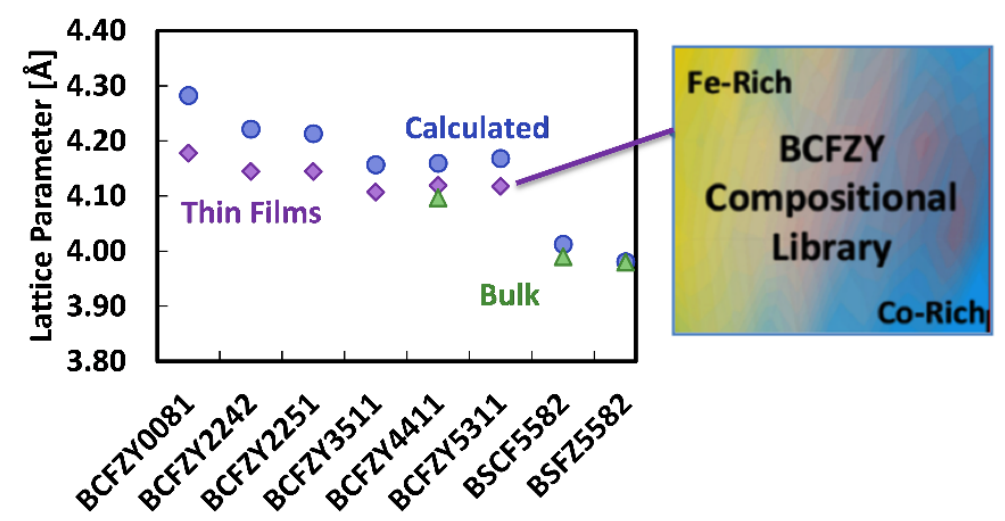

Figure S2. Calculated lattice parameters for all compositions of BCFZY, BSCF, and BSFZ as compared to the experimental bulk and thin film lattice parameters. Calculated lattice parameters trend well with experimental values. 
a)

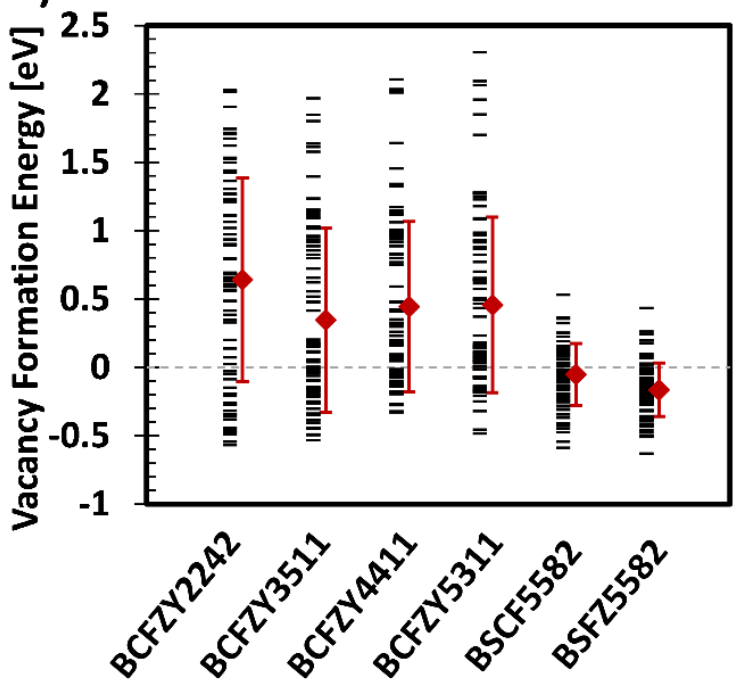

b)

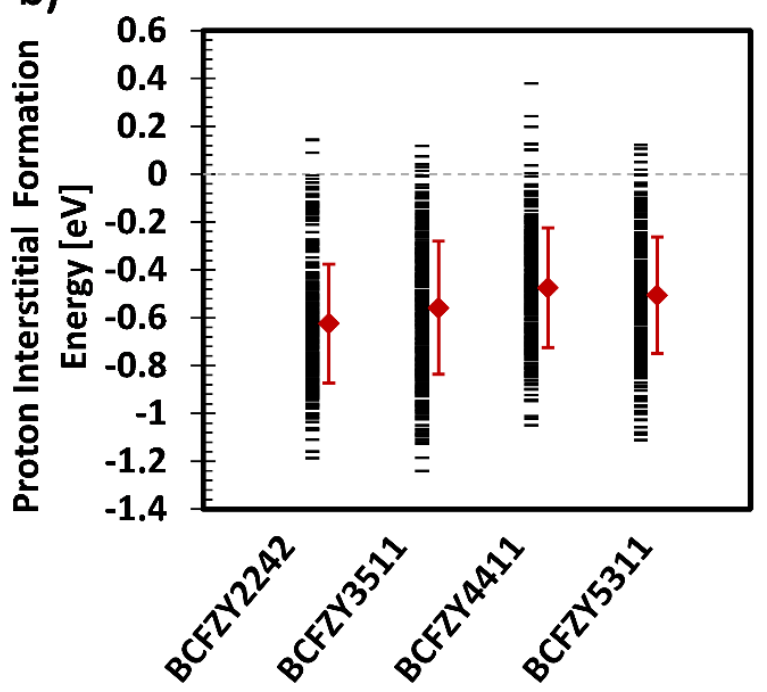

Figure S3. Distribution of a) oxygen vacancy formation energies for all compounds and b) proton interstitial formation energies for BCFZY compounds. The computed defect energies of all individual defects samples are shown by the black lines. The computed averages and standard deviations for each compound are shown with blue diamonds and lines.

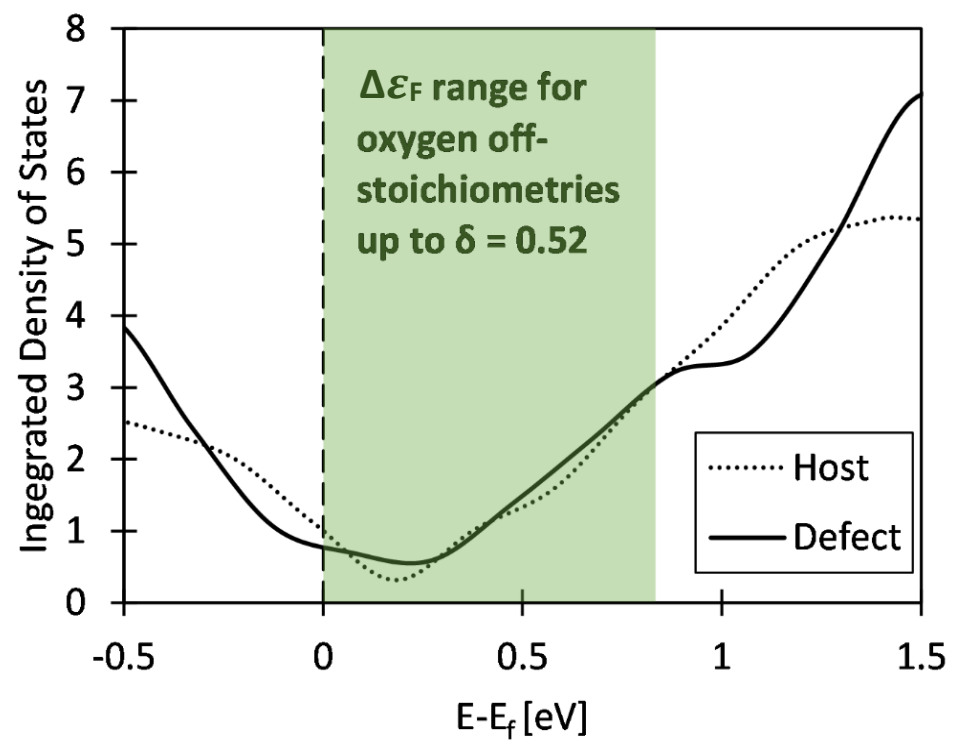

Figure S4. Comparison of the integrated density of states (DOS) of the Co and Fe states for the host (dotted) and oxygen deficient (solid) structures of BCFZY4411. The effective vacancy formation energy increases by less than $0.9 \mathrm{eV}$ at $\delta=0.52$ (see Figure 3c). The integrated DOS of the $\mathrm{Co}$ and $\mathrm{Fe}$ states for the host and oxygen deficient structures show good agreement over this range. This analysis validates the assumption of a rigid band structure for these hole-doped perovskite systems. 

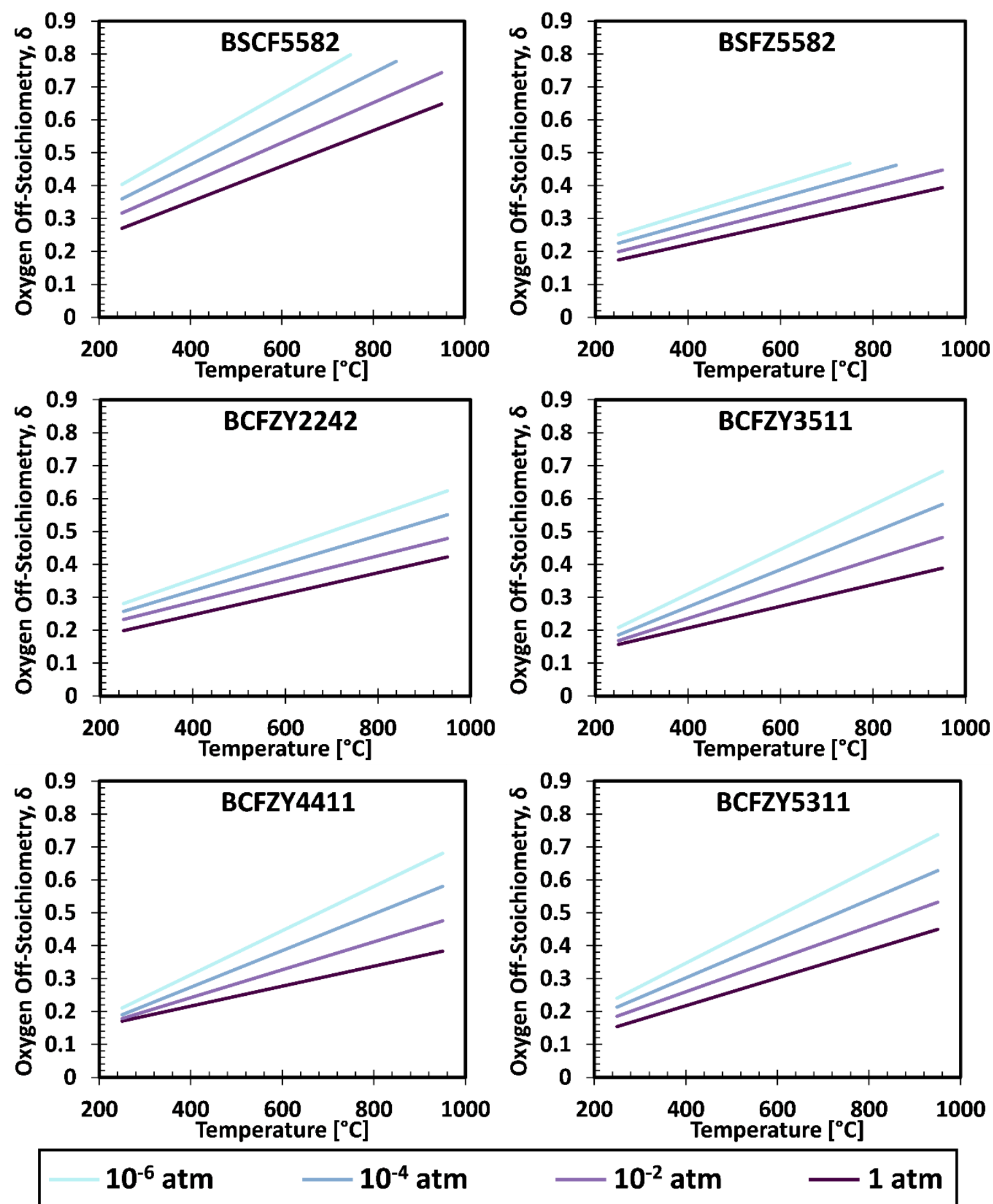

$10^{-2} \mathrm{~atm}$

$1 \mathrm{~atm}$

Figure S5. Computationally determined equilibrium oxygen off-stoichiometry under dry conditions for the six perovskites studied at $p_{\mathrm{O}_{2}}$ ranging from $10^{-6} \mathrm{~atm}$ to $1 \mathrm{~atm}$. 


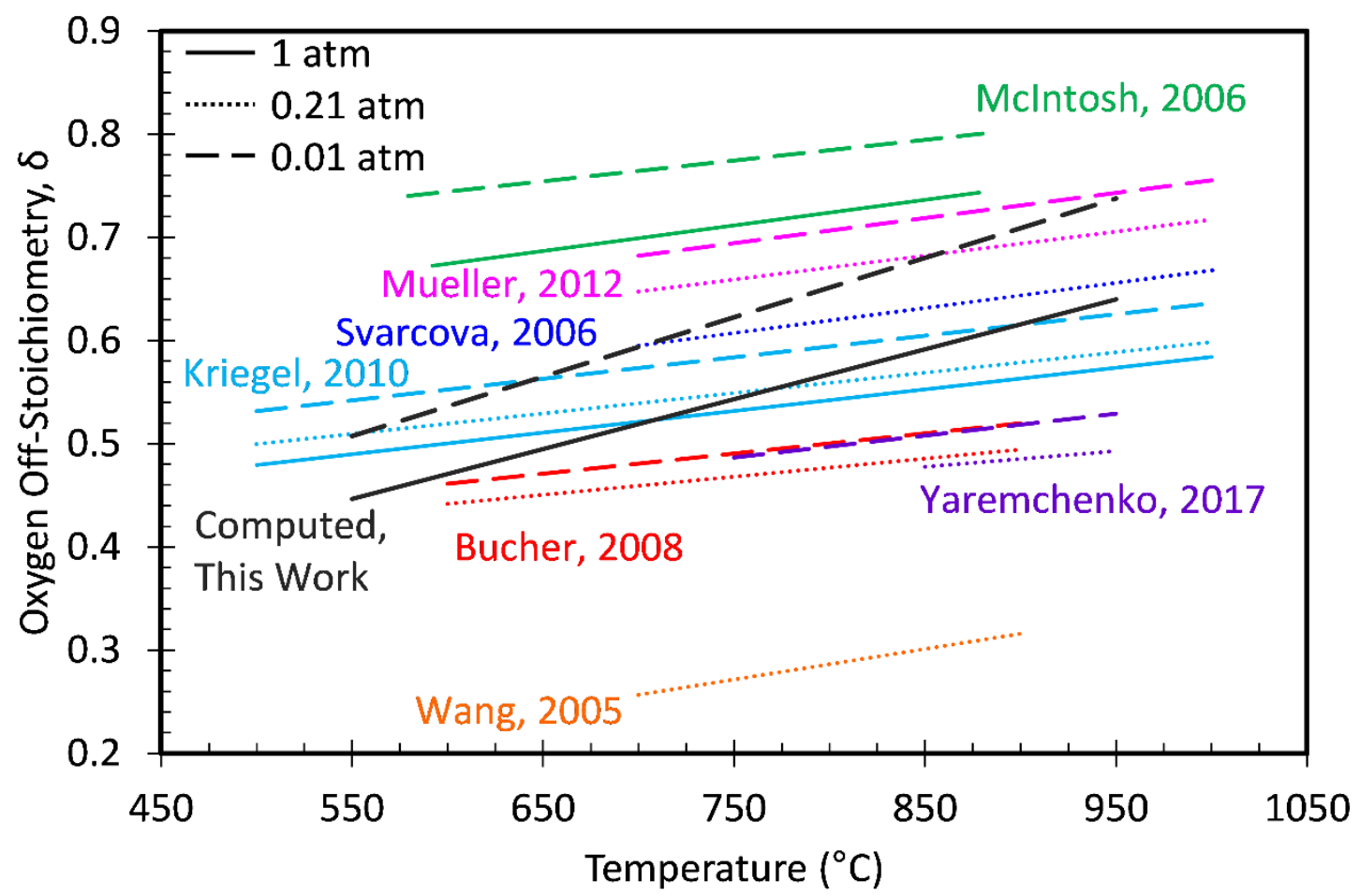

Figure S6. Comparison of computationally determined and various experimentally measured oxygen off-stoichiometry values for BSCF5582. ${ }^{17,23-28}$ 

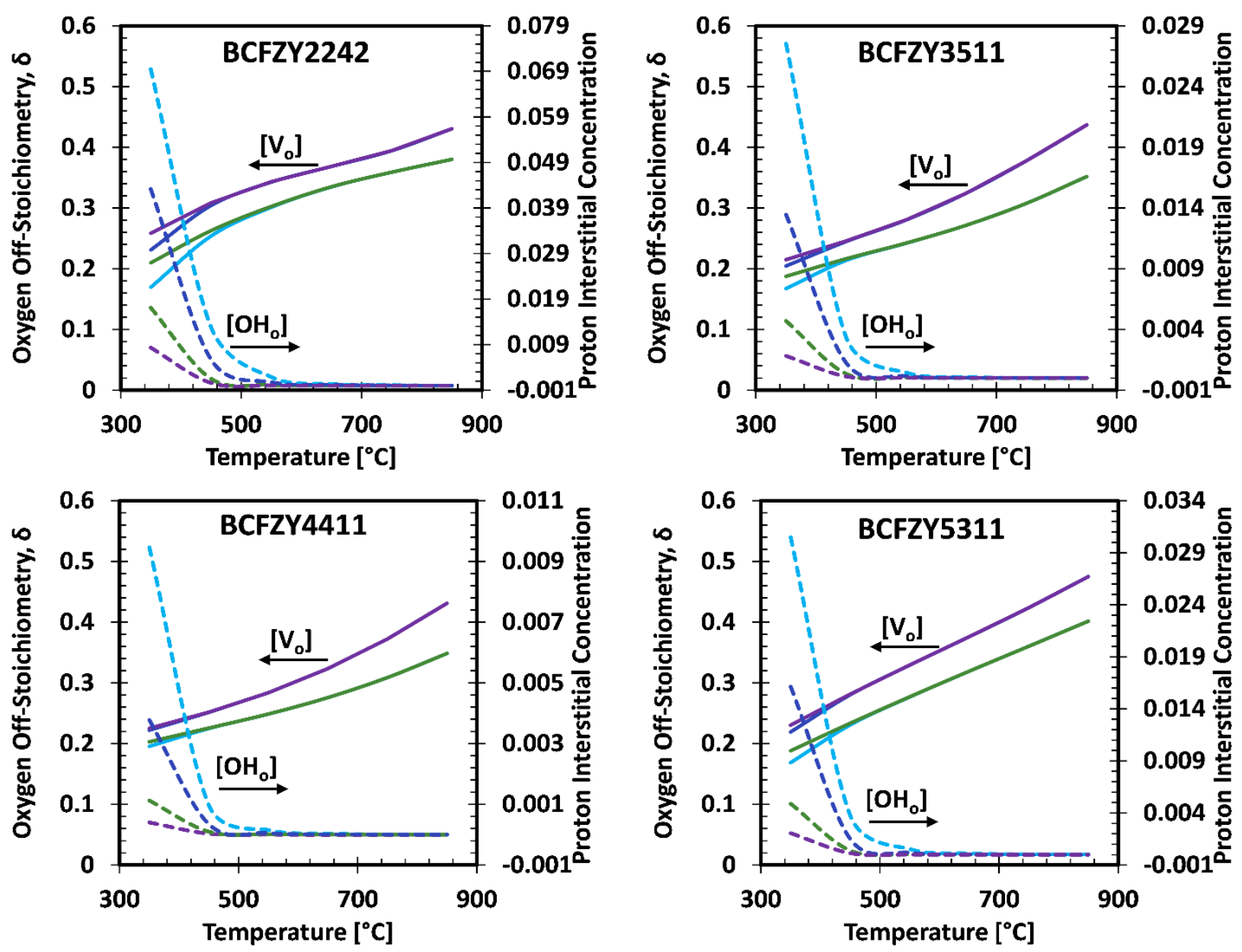

$$
\begin{array}{ll}
\mathrm{pO}_{2}=1 \text { atm, } \mathrm{pH}_{2} \mathrm{O}=10^{-2} \text { atm } & \mathrm{pO}_{2}=10^{-2} \text { atm, } \mathrm{pH}_{2} \mathrm{O}=10^{-2} \text { atm } \\
\mathrm{pO}_{2}=1 \text { atm, } \mathrm{pH}_{2} \mathrm{O}=10^{-4} \text { atm } & \mathrm{pO}_{2}=10^{-2} \text { atm, } \mathrm{pH}_{2} \mathrm{O}=10^{-4} \text { atm }
\end{array}
$$

Figure S7. Computationally determined equilibrium oxygen off-stoichiometry and proton interstitial concentration under wet conditions for BCFZY compositions at $p_{\mathrm{O}_{2}}=10^{-2} \mathrm{~atm}$ and $1 \mathrm{~atm}$ and $p_{\mathrm{H}_{2} \mathrm{O}}=$ $10^{-4} \mathrm{~atm}$ and $10^{-2} \mathrm{~atm}$. 


\section{Supplemental References}

1 Stevanović, V., Lany, S., Zhang, X., and Zunger, A. (2012). Correcting density functional theory for accurate predictions of compound enthalpies of formation: Fitted elementalphase reference energies. Physical Review B 85, 115104.

2 Paudel, T.R., Lany, S., d'Avezac, M., Zunger, A., Perry, N.H., Nagaraja, A.R., Mason, T.O., Bettinger, J.S., Shi, Y., and Toney, M.F. (2011). Asymmetric cation nonstoichiometry in spinels: Site occupancy in $\mathrm{Co}_{2} \mathrm{ZnO}_{4}$ and $\mathrm{Rh}_{2} \mathrm{ZnO}_{2}$. Physical Review B 84, 064109.

3 Osorio-Guillén, J., Lany, S., Barabash, S.V., and Zunger, A. (2006). Magnetism without Magnetic Ions: Percolation, Exchange, and Formation Energies of Magnetism-Promoting Intrinsic Defects in CaO. Physical Review Letters 96, 107203.

4 Wagman, D.D., Evans, W.H., Parker, V.B., Schumm, R.H., Halow, I., Bailey, S.M., Churney, K.L., and Nuttall, R.L. (1982). The NBS tables of chemical thermodynamic properties: Selected values for inorganic and $\mathrm{C}_{1}$ and $\mathrm{C}_{2}$ organic substances in SI units. Journal of Physical and Chemical Reference Data 11.

$5 \quad$ Kresse, G., and Furthmüller, J. (1996). Efficiency of ab-initio total energy calculations for metals and semiconductors using a plane-wave basis set. Computational Materials Science 6, 15-50.

6 Perdew, J.P., Burke, K., and Ernzerhof, M. (1996). Generalized Gradient Approximation Made Simple. Physical Review Letters 77, 3865.

$7 \quad$ Kresse, G., and Joubert, D. (1999). From ultrasoft pseudopotentials to the projector augmented-wave method. Physical Review B 59, 1758-1775.

8 Monkhorst, H.J., and Pack, J.D. (1976). Special points for Brillouin-zone integrations. Physical Review B 13, 5188-5192.

9 Takeda, T., and Watanabe, H. (1972). Magnetic Properties of the System $\mathrm{SrCo}_{1-\mathrm{x}} \mathrm{Fe}_{\mathrm{x}} \mathrm{O}_{3-\mathrm{y}}$. Journal of the Physical Society of Japan 33, 973-978.

10 MacChesney, J.B., Sherwood, R.C., and Potter, J.F. (1965). Electric and Magnetic Properties of the Strontium Ferrates. The Journal of Chemical Physics 43, 1907-1913.

11 Kawasaki, S., Takano, M., and Takeda, Y. (1996). Ferromagnetic Properties of $\mathrm{SrFe}_{1-\mathrm{x}} \mathrm{Co}_{\mathrm{x}} \mathrm{O}_{3}$ Synthesized under High Pressure. Journal of Solid State Chemistry 121, 174-180.

12 Nozaki, H., Janoschek, M., Roessli, B., Sugiyama, J., Keller, L., Brewer, J.H., Ansaldo, E.J., Morris, G.D., Takami, T., and Ikuta, H. (2007). Antiferromagnetic spin structure in $\mathrm{BaCoO}_{3}$ below $15 \mathrm{~K}$ determined by neutron and $\mu+\mathrm{SR}$. Journal of Physics and Chemistry of Solids 68, 2162-2165.

13 Deml, A.M., Stevanović, V., Muhich, C.L., Musgrave, C.B., and O'Hayre, R. (2014). Oxide enthalpy of formation and band gap energy as accurate descriptors of oxygen vacancy formation energetics. Energy \& Environmental Science 7, 1996.

14 Zunger, A., Wei, S.H., Ferreira, L.G., and Bernard, J.E. (1990). Special quasirandom structures. Physical Review Letters 65, 353-356.

15 van de Walle, A., Tiwary, P., de Jong, M., Olmsted, D.L., Asta, M., Dick, A., Shin, D., Wang, Y., Chen, L.Q., and Liu, Z.K. (2013). Efficient stochastic generation of special quasirandom structures. Calphad 42, 13-18.

16 van de Walle, A., Asta, M., and Ceder, G. (2002). The alloy theoretic automated toolkit: A user guide. Calphad 26, 539-553. 
17 Kriegel, R., Kircheisen, R., and Töpfer, J. (2010). Oxygen stoichiometry and expansion behavior of $\mathrm{Ba}_{0.5} \mathrm{Sr}_{0.5} \mathrm{Co}_{0.8} \mathrm{Fe}_{0.2} \mathrm{O}_{3-\delta}$. Solid State Ionics 181, 64-70.

18 Zakaria, N., Osman, R.A.M., and Idris, M.S. (2016). Structure refinement of $\mathrm{Ba}_{0.5} \mathrm{Sr}_{0.5} \mathrm{Co}_{0.8} \mathrm{Fe}_{0.2} \mathrm{O}_{3-\mathrm{d}}$ as cathode materials for intermediate temperature solid oxide fuel cells (IT-SOFC). AIP Conference Proceedings 1756, 090006.

19 Poetzsch, D., Merkle, R., and Maier, J. (2015). Proton uptake in the H+-SOFC cathode material $\mathrm{Ba}_{0.5} \mathrm{Sr}_{0.5} \mathrm{Fe}_{0.8} \mathrm{Zn}_{0.2} \mathrm{O}_{3-\delta}$ : transition from hydration to hydrogenation with increasing oxygen partial pressure. Faraday Discussions 182, 129-143.

20 Wei, B., Lü, Z., Huang, X., Liu, M., Li, N., and Su, W. (2008). Synthesis, electrical and electrochemical properties of $\mathrm{Ba}_{0.5} \mathrm{Sr}_{0.5} \mathrm{Zn}_{0.2} \mathrm{Fe}_{0.8} \mathrm{O}_{3-\delta}$ perovskite oxide for IT-SOFC cathode. Journal of Power Sources 176, 1-8.

21 Hinuma, Y., Hayashi, H., Kumagai, Y., Tanaka, I., and Oba, F. (2017). Comparison of approximations in density functional theory calculations: Energetics and structure of binary oxides. Physical Review B 96, 094102.

22 Shannon, R. (1976). Revised effective ionic radii and systematic studies of interatomic distances in halides and chalcogenides. Acta Crystallographica Section A 32, 751-767.

23 McIntosh, S., Vente, J.F., Haije, W.G., Blank, D.H.A., and Bouwmeester, H.J.M. (2006). Oxygen Stoichiometry and Chemical Expansion of $\mathrm{Ba}_{0.5} \mathrm{Sr}_{0.5} \mathrm{Co}_{0.8} \mathrm{Fe}_{0.2} \mathrm{O}_{3-\delta}$ Measured by in Situ Neutron Diffraction. Chemistry of Materials 18, 2187-2193.

24 Mueller, D.N., De Souza, R.A., Yoo, H.-I., and Martin, M. (2012). Phase Stability and Oxygen Nonstoichiometry of Highly Oxygen-Deficient Perovskite-Type Oxides: A Case Study of $(\mathrm{Ba}, \mathrm{Sr})(\mathrm{Co}, \mathrm{Fe}) \mathrm{O}_{3-\delta}$. Chemistry of Materials 24, 269-274.

25 Švarcová, S., Wiik, K., Tolchard, J., Bouwmeester, H.J.M., and Grande, T. (2008). Structural instability of cubic perovskite $\mathrm{Ba}_{\mathrm{x}} \mathrm{Sr}_{1-\mathrm{x}} \mathrm{Co}_{1-\mathrm{y}} \mathrm{Fe}_{\mathrm{y}} \mathrm{O}_{3-\delta}$. Solid State Ionics 178 , 1787-1791.

26 Bucher, E., Egger, A., Ried, P., Sitte, W., and Holtappels, P. (2008). Oxygen nonstoichiometry and exchange kinetics of $\mathrm{Ba}_{0.5} \mathrm{Sr}_{0.5} \mathrm{Co}_{0.8} \mathrm{Fe}_{0.2} \mathrm{O}_{3-\delta}$. Solid State Ionics 179, 1032-1035.

27 Yaremchenko, A.A., Khalyavin, D.D., and Patrakeev, M.V. (2017). Uncertainty of oxygen content in highly nonstoichiometric oxides from neutron diffraction data: example of perovskite-type $\mathrm{Ba}_{0.5} \mathrm{Sr}_{0.5} \mathrm{Co}_{0.8} \mathrm{Fe}_{0.2} \mathrm{O}_{3-\delta}$. Journal of Materials Chemistry A 5, 3456-3463.

28 Wang, H., Yang, W., Tablet, C., and Caro, J. (2005). Oxygen diffusion in oxide crystals tracing new routes to identify the rate limiting step of oxygen permeation through perovskite membranes. Journal of Diffusion Fundamentals 2, 1-15. 